\title{
Meningkatkan Pemahaman Masyarakat Terhadap Keagamaan Melalui Program Pendidikan dan Sosial Keagamaan
}

\author{
Ira Suryani ${ }^{1 *}$, Abdul Rajab Tanjung ${ }^{2}$, Rahma Dewi Siregar ${ }^{3}$, Annaria Saleha \\ Siregar ${ }^{4}$ \\ ${ }^{1}$ Universitas Islam Negeri Sumatera Utara Medan, Indonesia \\ ${ }^{2}$ Universitas Islam Negeri Sumatera Utara Medan, Indonesia \\ ${ }^{3}$ Universitas Islam Negeri Sumatera Utara Medan, Indonesia \\ ${ }^{4}$ Universitas Islam Negeri Sumatera Utara Medan, Indonesia \\ * Corresponding Author. E-mail: 1 irasuryani@uinsu.ac.id
}

Receive: $24 / 05 / 2021$

Accepted: 24/09/2021

Published: 01/10/2021

\begin{abstract}
Abstrak
Artikel ini adalah bagian dari studi untuk mengukur kualitas hidup keagamaan Muslim di desa Lantosan I dalam hal pemahaman masyarakat terhadap Keagamaan melalui program pendidikan dan sosial keagamaan dan studi praktek sosial. Melalui campuran metode pengumpulan data yang terdiri dari kuesioner, wawancara dengan tokoh masyarakat dan ahli serta diskusi dengan kelompok fokus (FGD), studi ini menemukan bahwa kemampuan umat Islam di Desa Lantosan I untuk memahami Keagamaan dan kemampuan masyarakat untuk menerapkan peran sosial-keagamaan yang didasarkan pada pemahaman al-Quran sudah cukup baik di tingkat. Faktor lain mengapa kualitas pemahaman masyarakatpada al-Quran tidak maksimal adalah kurangnya motivasi dari keluarga dan lingkungan sosial untuk melaksanakan kegiatan keagamaan, untuk mensosialisasikan dan meningkatkan perilaku dalam ibadah.
\end{abstract}

Kata Kunci: KKN, Pengabdian Masyarakat, Pendidikan Sosial dan Keagamaan.

\section{Improving Public Understanding of Religion Through Religious Education and Social Programs}

\begin{abstract}
This article is part of a study to measure the quality of religious life of Muslims in Lantosan I village in terms of people's understanding of religion through educational and socio-religious programs and studies of social practices. Through a mixture of data collection methods consisting of questionnaires, interviews with community leaders and experts as well as discussions with focus groups (FGD), this study found that the ability of Muslims in Lantosan I Village to understand Religion and the community's ability to implement socio-religious roles based on on the understanding of the Koran is quite good at the level. Another factor why the quality of people's understanding of the Koran is not optimal is the lack of motivation from the family and social environment to carry out religious activities, to socialize and improve behavior in worship.
\end{abstract}

Keywords: Community Service, Community Service, Social and Religious Education. 



\section{Pendahuluan}

Desa Lantosan I sebelum menjadi wilayah administrasi pemerintahanadalah salah satu wilayah perkampungan yang dibawahi oleh seorang kepala kampung dan berada dalam wilayah pemerintahan Distrik Portibi yang secara administrasi juga menjadi Kecamatan Portibi.

Desa Lantosan I mempunyai jumlah penduduk 5.102 Jiwa dari 1.447 kartu keluarga, dengan asumsi jumlah penduduk lakilaki 2.519 jiwadan perempuan sebanyak 2.583 jiwa yang tersebar di delapan dusun. Warga Desa Portibi sebagian besar hidup bekerja di sektor pertanian, usaha ternak sapi, itik dan ayam. Semua diusahakan secara tradisional, di daerah topografi yang datar. Hanya sedikit di antaranya yang bekerja di kantor pemerintah. Latar belakang pendidikan masyarakatnya juga masih sangat rendah. Hanya sekitar 3 persen diantaranya yang bergelar sarjana, sebagian besar hanya mengenyam pendidikan sampai sekolah menengah pertama dan sekolah menengah atas. Sarana peribadatan adalah hal yang penting dalam hidup bermasyarakat karena sarana ini tempat untuk mengisi kebutuhan rohani untuk masyarakat yang perlu disediakan di lingkungan perdesaan namun hal ini tidak mudah untuk langsung dibangun namun harus sesuai ketetapan, peraturan dan keputusan masyarakat yang bersangkutan. Dalam hal kegamaan penduduk Desa Portibi sebagian besar menganut agama islam. Setiap dusun di Desa Portibi terdiri dari memiliki sarana peribadatan berupa Masjid yang digunakan oleh warga dan masyarakat setempat. Dalam rangka menfasilitasi semangat warga dalam beribadah maka program KKN Mahasiswa UIN Sumatera Utara diwujudkan dengan berbagai program pembinaan dan keilmuan untuk masyarakat agar pemahaman masyarakat dapat bertambah dan terwujudkan kembali dalam bentuk aqidah dan ibadah yang benar serta sesuai dengan tuntutan syariat yang dibawa oleh Muhammad Sallallahu 'alaihi wasallam.

\section{Metode}

\section{Pendekatan dan Metode Penelitian}

Metode penelitian yang kami lakukan dalam pelaksanaan $\mathrm{kkn}$ ini ada dua penelitian yang pertama adalah dengan pendekatan penelitian kualitatif di mana penelitian kualitatif itu sendiri berbeda dengan penelitian lainnya. Di mana penelitian kualitatif ini merupakan metode yang lebih sering di lakukan ketika turun langsung ke lapangan dengan menggunakan beberapa langkah penelitian Metode penelitian kualitatif adalah sebagai metode ilmiah sering digunakan dan dilaksanakan oleh sekelompok peneliti dalam bidang ilmu sosial, antropologi dan sejumlah penelitian perilaku lainnya termasuk ilmu pendidikan. Penelitian kualitatif di bidang sosialisasi kemasyatakatan tidak dilaksanakan di laboratorium tetapi di lapangan tempat peristiwa pendidikan berlangsung secara natural atau alami.

Selain metode penelitian kualitatif kami menggunakan metode penelitian tindakan kelas dalam pelaksanaan bidang bendidikan dimana penelitian tindakan kelas yang sudah kami pelajari tentang bagaimana pengelolaan kelas dengan baik, fungsi susunan bangku dalam menentukan tempat duduk sudah diterapkan dalam kegiatan kkn kali ini dengan memfokuskan Kegiatan ini dilaksanakan setiap hari sekolah (senin-sabtu) di tiga SD dan satu dengan berbagai program pembiasaan yang positif seperti: shalat berjama'ah, tahsinul Qira'ah, taujihad murabbi, materi tazkiyatun nafs, menjenguk orang sakit, dan mabit (malam bina iman dan takwa).

\section{Latar Penelitian}

Dalam observasi, mahasiswa kkn UIN SU Medan melakukan penelitian langsung ke lapangan di Desa Lantosan I, Kecamatan Portibi, Kabupaten Padang Lawas Utara, untuk melihat langsung kondisi pendidikan dan moderasi beragama. 


\section{Alat Pengumpulan Data}

Alat pengumpulan data adalah teknik dalam mengumpulkan data yang akan dituliskan dalam laporan penelitian berupa:

1. Wawancara adalah kegiatan tanya jawab dengan informan guna mendapatkan informasi langsung.

2. Observasi yaitu pengamatan secara intensif dan langsung selama penelitian serta riset lapangan guna untuk membuktikan kebenaran dari kedua informan kunci maupun utama.

\section{Studi dokumentasi}

\section{Menyiapkan data dalam tabel atau program kerja agar mudah mempresentasikannya di lapangan.}

\section{Hasil dan Pembahasan}

Kegiatan ini difokuskan kepada sekolah-sekolah yang ada di Desa Portibi dengan tujuan untuk meningkatkan wawasan peserta didik tentang agama islam berdasarkan tuntunan Rasulullah shallallahu 'alaihi wasallam. Kegiatan inidilaksanakan setiap hari sekolah (senin-sabtu) di tiga SD dan satu dengan berbagai program pembiasaan yang positif seperti: shalat berjama'ah,tahsinul Qira'ah, taujihad murabbi, materi tazkiyatun nafs, menjenguk orang sakit, dan mabit (malam bina iman dan takwa). ${ }^{1}$

Dalam melaksanakan kegiatan ini, tim KKN memasukkan surat TKN. Sebuah penelitian menunjukkan bahwa tarbiyah islamiyah mampu memberikan nilai-nilai karakter pada para peserta permohonan mengajar kepada Kepala Sekolah masingmasing. Setelah mendapatkan persetujuan dari Kepala Sekolah, Tim KKN membuat jadwal pengajar yang bergantian setap harinya.

Dalam proses belajar mengajar di kelas, kegiatan diawali dengan ketua kelas maju ke depan memimpin doa sebelum belajar kemudian dilanjutkan dengan materi yang sesuai dengan tema yang ada di buku pembelajaran.
Diakhir pembelajaran, siswa-siswi di berikan hafalan Alquran dan doa-doa harian. Kegiatan ini didukung oleh masing-masing kepala sekolah beserta guru dan siswa-siswi sehingga tidak ada hambatan berarti pada pelaksanaan kegiatan ini.

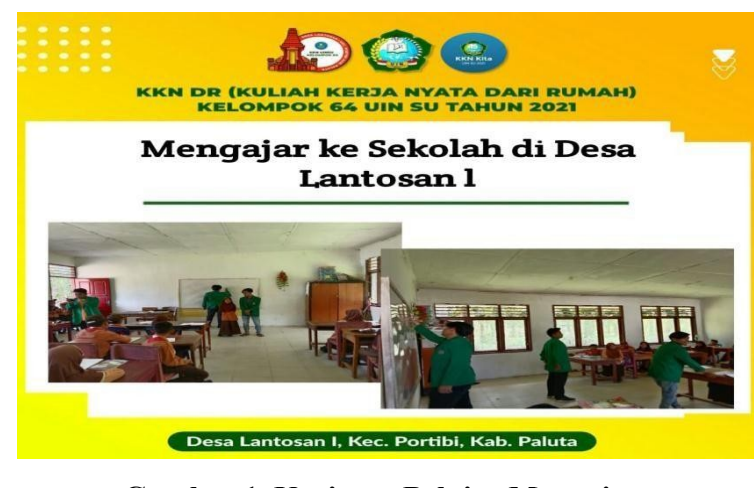

Gambar 1. Kegiatan Belajar Mengajar

Taklim Muslimah Kegiatan ini dikhususkan untuk para wanita, baik ibu-ibu ataupun remaja dengan tujuan memberikan pemahaman dan wawasan Islam serta menjadi ajang silaturahmi bagi masyarakat Desa Lantosan. Majelis Taklim adalah salah satu sarana pembentuk akhlak dan kepribadian yang luhur sekaligus sebagai stabilisator dari seluruh gerakaktivitas kehidupan umat Islam Indonesia, sehingga perlu mendapatkan perhatian dan dukungan dari masyarakat agar tercipta keterpaduan potensi intelektual dan spiritual dalam usaha menghadapi perubahan zaman yang maju dan dinamis. ${ }^{2}$

Kegiatan Taklim Muslimah iniberjalan dengan baik pada setiap malam jumat sehingga seluruh masyarakat Desa Lantosan bisa merasakan keberadaan program tersebut. Kegiatan ini menjadi motivasi bagi warga Desa Lantosan untuk memperbaiki diri untukmenjadi yang lebih baik. Langkah- langkah dan hasil kegiatan: Dalam melaksanakan kegiatan ini, panitia terlebih dahulu melakukan musyawarah internal yang diadakan di posko KKN akhwat. Hal yang dibahas dalam musyawarah tersebut adalah: target, waktu dan tempatkegiatan yang sesuai dengan masyarakat Desa Lantosan.

Setelah menentukan waktu dan tempat, dilanjutkan dengan bersilaturahmi ke rumah bapak dusun untuk meminta izin melaksanakan kegiatan Taklim Muslimah. Setelah mendapat izin, panitia mulai menyosialisasikan kegiatan tersebut dengan cara mengundang masyarakat dan tokoh agama di desa tersebut, seperti ibuibu dusun dan ketua-ketua majelis taklim. Tim juga membuat selebaran brosur untuk dibagikan 
kepada masyarakat Desa Lantosan, khususnya muslimah. Dana kegiatan ini bersumber dari kas bendahara KKN. Peserta kegiatan kurang lebih 50 orang yang terdiri dari ibu-ibu dan remaja. Kegiatan majelis taklim yang telah dilakukan adalah proses pendidikan yang berorientasikan kepada internalisasi nilai-nilai agama sehingga para peserta harus mampu merefleksikan tatanan normatif yang mereka pelajari terutama dalamrealitas kehidupan yang sesungguhnya, khususnya untuk mengembangkan sikap dan pemahaman keagamaan jama'ah di majelis ta'lim tersebut. ${ }^{3}$

Kegiatan ini didukung dengan adanya kerja sama dari Tim KKN Akhwat Lantosan, dukungan dari aparat Desa Lantosan, khususnya ibu desa sendiri yang selalu menyempatkan waktu untuk hadir dalam kegiatan ini, serta partisipasi dari ibu-ibu majelis taklim untuk menghadirkan anggotanya. Kendala yang dihadapi dalam kegiatan ini adalah kurangnya alat transportasi ke tempat pelaksanaan sehingga menyebabkan kegiatan tersebut terlambat dilaksanakan. Tindakan solutif adalah dengan berangkat ke lokasi kegiatan di awal waktu.

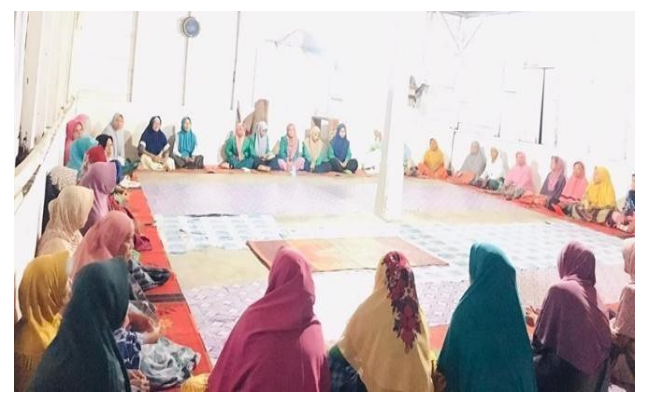

Gambar 2. Tahsinul Qira'atil Qur'an

Tujuan kegiatan ini adalah untuk memperbaiki bacaan Alquran sesuai dengan kaidah-kaidah tajwid yang benar. $^{4}$ Pendidikan al-Qur'an adalah pendidikan berbasis al-Qur'an yang mengupas masalah al-Qur'an dalam makna; membaca (tilawah), memahami (tadabbur), menghafal (tahfizh), dan mengamalkan serta mengajarkan atau memeliharanya melalui berbagai unsur. $^{5}$

Berbagai upaya ini dikemas dalam bentuk program Tahsinu Qira'atil Qur'an merupakan program yang berbentuk kelompok (halaqah) yang dilaksanakan setiap pekan sesuai dengan waktu yang disepakati. Langkah-langkah dan hasil kegiatan: Tim KKN bersilaturahmi di setiap dusun dan mendata ibu-ibu yang sudah selesai dalam pembelajaran DIROSA, kemudian mengajak mereka untuk belajar tahsin dengan membentuk halaqoh. Mengisi halaqoh tahsin dengan memberikanmateri dari buku Mahir Tahsin, memperbaiki bacaan dan menyetorkan hafalan pada juz 30 .

Kegiatan ini didukung oleh aparat desa dan masyarakat setempat khususnya ibu-ibu majelis taklim yang begitu semangat dalam berpartisipasi pada kegiatan ini. Kendala yang dihadapi adalah kurangnya halaqoh tahsin yang terbentuk dikarenakan tidak adanya follow up dari pengajaran DIROSA setelah penarikan mahasiswa KKN sebelumnya. Oleh karena itu, tindakan solutif adalah mengadakan follow up dari pengajaran DIROSA setelah penarikan KKN sehingga ibu-ibu bisa melanjutkan dan menyelesaikan pengajaran DIROSA yang dilanjutkan dengan halaqoh tahsin.

Program kerja ini dilaksanakanoleh Tim KKN Desa Lantosan di empat TKA/TPA yang ada di Desa Lantosan. Pengajaran TKA/TPA yang dilakukan mahasiswi KKN meliputi pembimbingan santri dalam membaca Iqra' dan Alquran dengan tajwid yang benar. Sebagai tambahan, santri juga diajarkan dan dilatih untuk menghapalkan doa-doa harian, surahsurah pendek dan adab- adab santri. Kegiatan ini diawali dengan musyawarah Tim KKN akhwat mengenai pengajaran TKA/TPA yang ada di Desa Lantosan. Kemudian melakukan silaturahmi ke beberapa rumah kepala dusun, rumah guru mengaji dan pembina TPA sekaligus memintaizin untuk membina dan membantu dalam mengajar TPA. Pengajaran TPA dimulai dengan membuka majelis dan membaca doa sebelumbelajar bersama yang kemudian dilanjutkan dengan mengaji dan memperbaiki bacaan serta membimbing santri untuk menghafal surah-surah pendek dan doa-doa harian. 
Jurnal Edumaspul, 5 (2), Year 2021- 18

(Ira Suryani, Abdul Rajab Tanjung, Rahma Dewi Siregar, Annaria Saleha Siregar)

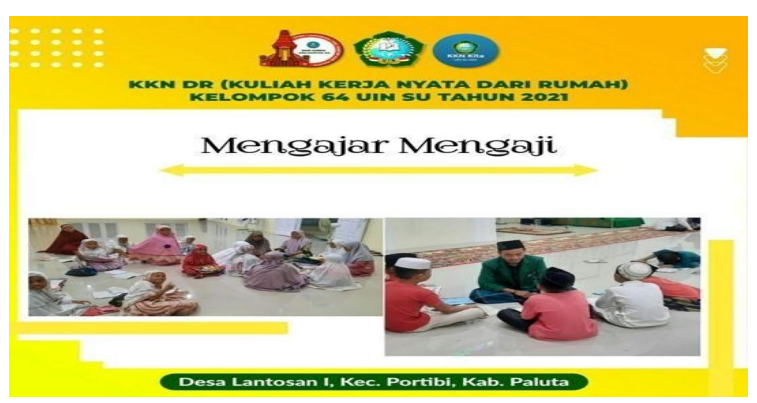

Gambar 3. Mengajar Mengaji

Sumbangan untuk Anak Yatim. Kegiatan ini tujukan kepada paraanak yatim yang ada di daerah Lantosan guna memenuhi program KKN ini. Dengan penuh rasa berbagi, para mahasiswa KKN membagikan sejumlah uang tunai masingmasing Rp 500.000 kepadapara anak yatim.

Dalam kegiatan ini ada 5 anak yatim yang ada di daerah Lantosan yang mana ada anak yang tidak memiliki ayah atau ibu karena sudah meninggal. Kegiatan ini dilaksanakan setelah melaksanakan sholat jumat di desa Lantosan dengan didampingi warga dan kepala Desa Lantosan.

Kegiatan ini bertujuan untuk menumbuhkan rasa kemanusiaan dalam diri masyarakat sekitar bahwasannya masih banyak orang di luar sana yang membutuhkan. Kegiatan ini didukung dengan adanya donatur yang memenuhi kebutuhan sebagian warga yang kemudian disalurkan oleh tim KKN UIN Sumatera Utara sehingga program ini berjalan lancar tidak menemui kendala yang berarti.

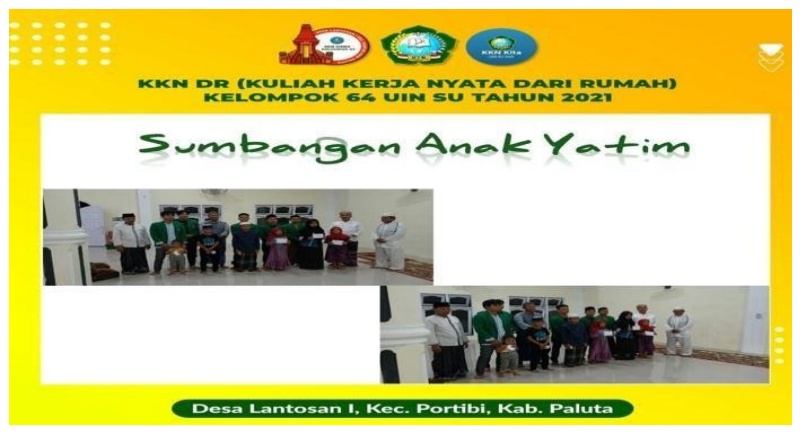

Gambar 4. Sumbangan Anak Yatim

STATISTIK DESA LANTOSAN I KECAMATAN PORTIBI KABUPATEN PADANG LAWAS UTARA

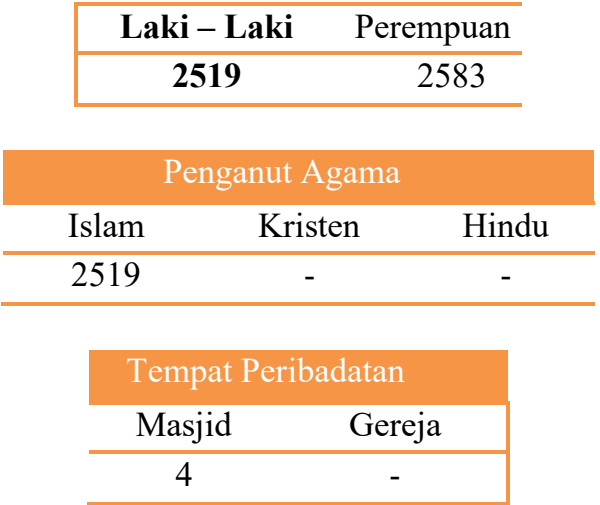

\begin{tabular}{|c|c|}
\hline \multicolumn{2}{|c|}{ Ruang Moderasi Beragama } \\
\hline Desa & Alasan \\
\hline $\begin{array}{c}\text { Desa } \\
\text { Lantosan I }\end{array}$ & $\begin{array}{l}\text { Tidak adanya Pertentangan Antar } \\
\text { Masyarakat yang mengatas } \\
\text { namakan agama }\end{array}$ \\
\hline $\begin{array}{c}\text { Desa } \\
\text { Mangaledang }\end{array}$ & $\begin{array}{l}\text { Sebab adanya pembentukan } \\
\text { kelompok antar masyarakat } \\
\text { berdasarkan suku marga yang } \\
\text { dapat menyebabkan lemahnya } \\
\text { pelaksanaan tentang keagamaan } \\
\text { dalam masayarakat. }\end{array}$ \\
\hline $\begin{array}{c}\text { Desa } \\
\text { Janji Matogu }\end{array}$ & $\begin{array}{l}\text { Tidak adanya Pertentangan Antar } \\
\text { Masyarakat yang mengatas } \\
\text { namakan agama }\end{array}$ \\
\hline $\begin{array}{l}\text { Desa Hulu } \\
\text { Sihapas }\end{array}$ & $\begin{array}{l}\text { Sebab adanya pembentukan } \\
\text { kelompok antar masyarakat } \\
\text { berdasarkan suku marga yang } \\
\text { dapat menyebabkan lemahnya } \\
\text { pelaksanaan tentang keagamaan } \\
\text { dalam masayarakat. }\end{array}$ \\
\hline $\begin{array}{c}\text { Desa } \\
\text { Hutaraja }\end{array}$ & $\begin{array}{lr}\text { Tidak adanya Pertentangan Antar } \\
\text { Masyarakat } & \text { yang } \\
\text { mengatasnamakan agama } & \end{array}$ \\
\hline
\end{tabular}

\section{Simpulan}

Berdasarkan uraian program kerja dan pelaksanaan Program Kerja Mahasiswa Universitas Islam Sumatera Utara tahun akademik 2020/2021 di Desa Lantosan I, Kec. Portibi, Kab. Padang Lawas Utara, maka dapat disimpulkan bahwa pelaksanaan KKN Mahasiswa UIN Sumatera Utara berjalan 
dengan baik. Program kerja yang telah disukseskan berjumlah 13 program kerja dengan rincian 8 program pendidikan Islam dan Al Qur'an serta 5 program kerja sosial. Program KKN ini berhasil memberikan pengalaman dakwah secara langsung kepada para mahasiswa sehingga akan terbentuk keterampilan dalam merumuskan dan merencanakan suatu program dakwah, sekaligus memberikan bahan masukan dan evaluasi perbaikan.

\section{Daftar Pustaka}

[1] Wijaya, H. \& Nurhidayah. (2020). Pembelajaran Metode Dirosa di Desa Majannang Kabupaten Gowa. Wahatul Mujtama: Jurnal Pengabdian Masyarakat.

https://komunitaskitahemat.com/index. php/wahatul/article/view/138.

[2] Iskandar \& Amirullah. (2020). Pelaksanaan Dirasah Qur'aniyyah Sebagai Upaya Peningkatan Kualitas Baca Al-Qur'an di Desa Tukamasea Kabupaten Maros. Wahatul Mujtama: Jurnal Pengabdian Masyarakat. https://journal.stiba.ac.id/index.php/wa hatul/article/view/135.

[3] Mariam. (2019). Peran Majelis Taklim dalam Pemberdayaan untuk Membentuk Kepribadian Muslimah. Lembaran Masyarakat: Jurnal Pengembangan Masyarakat, 5(2). http://103.20.188.221/index.php/lbrma sy/article/view/2471.

[4] Hakim, Rosniati. (2014). Pembentukan Karakter Peserta Didik Melalui Pendidikan Berbasis Alquran. Jurnal Pendidikan Karakter, 2(1). http://dx.doi.org/10.21831/ipk.v0i2.278 8.

[5] Irfan. (2017). Penerapan Program Tarbiyah Islamiyah dalam Pembentukan Karakter Peserta Didik pada SMP IT Wahdah Islamiyah Makassar. Skripsi. Makassar: UIN Alauddin Makassar.

\section{Profil Penulis 1}

Dr.Hj.Ira Suryani MSi, lahir di Medan 13 juli 1967, Dosen Fakultas IImu Tarbiyah dan Keguruan, dan menjadi pembimbing lapangan kelompok 64. Riwayat pendidikan MIN Medan tamat 1980, MTSn Medan tamat 1983, MAN Medan tamat 1986, S1 PAI IAIN tamat 1992, S2 PWD USU tamat 2001, S3 PEDI tamat 2016.

\section{Profil Penulis 2}

Abdul Rajab Tanjung, lahir di Simangambat Julu, 16 November 2000. Pernah menempuh pendidikan di SD 102050 Simangambat Julu, kemudian melanjutkan pendidikan SMP Negeri 1 simangambat dan lulus pada tahun 2015. Lalu, melanjutkan pendidikan ke jenjang sekolah menengah Kejuruan di SMK N 1 Padang Sidempuan dan lulus pada tahun 2018. Dan sekarang sedang melaksanakan pendidikan di UIN Sumatera Utara Medan di Jurusan Hukum Pidana Islam.

\section{Profil Penulis 3}

Rahma Dewi Siregar, Bertempat tinggal di Desa Mangaledang, Kecamatan Portibi, Kabupaten Padang Lawas Utara, Lahir di Desa mangaledang 29 ,Mei , 1999. Saya pernah menempuh Pendidikan di Desa SDN 101540 Mangaledang Lama, kemudian Melanjutkan Pendidikan Tingkat SMP Di Madrasah Tsanawiyah Yayasan Pendidikan Karya Setia PadangSidimpuan (MTS YPKS) Lulus Pada tahun 2015 dan setelah lulus dari situ saya melanjutkan pendidikan tingkat SLTA di Madrasah Aliyah Negeri 1 Padangsidimpuan (MAN 1 Padangsidimpuan) dan Lulus Pada Tahun 2018. Dan sekarang sedang melaksanakan Pendidikan di UIN sumatera Utara Medan Jurusan Hukum ekonomi syariah sedang menjalani semester VII. 


\section{Profil Penulis 4}

Annaria Saleha Siregar, lahir 21 tahun yang lalu di Labuhan-Labo, tepatnya pada tanggal 16 Mei 2000. Berdomisili di Kab. Padang Lawas Utara, Sumatera Utara. Pernah menempuh pendidikan di SDN 101580 Aek Haruaya, lulus pada tahun 2012. Kemudian, melanjutkan jenjang pendidikan menengah pertama di MTS.s Al-Mukhtariyah Gunung Raya, lulus pada tahun 2015. Selanjutnya, menempuh jenjang pendidikan menengah atas di MAN 2 Model Padangsidimpuan, lulus tahun 2018. Dan sekarang tercatat sebagai Mahasiswi jurusan Pendidikan Bahasa Arab (PBA), Fakultas Ilmu Tarbiyah dan Keguruan (FITK), UIN-Sumatera Utara, Medan. Bisa dikunjungi melalui email: Rainiasals@gmail.com dan ig: @annariasalehasiregar. 